\title{
From the Publisher's Side
}

Dear All,

I am pleased to introduce second issue of SUFFREC annual publication The Initiation. This issue's main topics are Biodiversity, Climate change, Non Timber Forest Product (NTFP) and newly emerged Socio-political issues in natural resource management. We are honored in this issue to have the insights and views of naturalists from Nepal and India also. Financial support and managerial contribution from various parties make their concrete roadmap for coordination with us on behalf of nature conservation. SUFFREC is committed to ensuring that all contributors for this publication have access to share clear and up to date information about our organization.

No doubt the newly emerging problem of human induced climate change first came to attention of global public when Intergovernmental Panel on Climate Change (IPCC) published its first assessment report in 1990. Now, climate change is not the concern of environmentalist/naturalist and development policy makers or practitioners only, it is the agenda of SAARC Summit, G-8 Summit and UN General Assembly including the entire global forum which are intended to the sustainable world. From the Rio Earth Summit 1992, environmental issues came in front, which was further enforced by Millennium Development Goals (MDGs) set in 2000 and Johannesburg Summit 2002. No one should care about other things if our steps are forwarded by the pivotal theme, "Think Globally, Act Locally", that is what we hope. But there are ample of evidence of distortion of living planet which is human induced. Newly emerging environmental challenges are demanding proactive initiation of global public to sustain the earth and its beauties to the next generation, which can act as step stone.

To address underlying factor for the nature conservation, The Initiation is here with collective endeavors. I have found unlimited resources within this folder and equally see the gaps to create new research ideas based on our knowledge perfects traveling with mind meandering journey. I believe that the subject matters in this publication will not only give the recurrent scenarios of existing Nepalese efforts towards the sustainable development, they will also stimulate further issues among Nepalese environmentalists/naturalists. I hope this task will receive the unprecedented height of success in the field of conservation of natural heritage.

From the side of publisher, my special thanks goes to our distinguished advisors Dr. Uday Raj Sharma, Dr. Tirtha Bahadur Shrestha, Dr. Madhav Bahadur Karik, Dr. Krishna Chandra Paudel and Mr. Arun Dhakal for their continuous guidance in the publication campaign and the authors for their valuable articles contributions to this issue. The whole time efforts of Shambhu Paudel for coordinating the publication campaign and Bharat Gotame for his outstanding contribution to entire range of activities, which are concluded by SUFFREC during this period, are felt precious.

I hope coming issue will be success to overcome the comments and suggestions from previous two issues. So, I openly appeal to all readers for their suggestions. I, further hope, you will not miss the appointment for next issue.

Best wishes and Greetings on the occasion of Happy Vijaya Dashami and Deepawali 2065.

\section{Bishnu Prasad Thapaliya}

Chairperson, SUFFREC

September, 2008 